\title{
Approaches to Improve Solubility, Stability and the Clinical Potential of Andrographolide: A Review
}

\author{
Maurya Rahul, Thirupataiah Boini, Misro Lakshminarayana, Thulasi Radhakrishnan, Rohit Kolangarakalam Sudayadas \\ National Ayurveda Research Institute for Panchakarma, Cheruthuruthy, Thrissur, Kerala, INDIA.
}

\begin{abstract}
Andrographolide (AGL) is an active phytoconstituent of Andrographis paniculata, which is chemically a diterpenoid lactone ring. The various pharmacological activities of this compound are reported but a clinically remarkable effect was not observed due to their poor aqueous solubility and instability in different physiological conditions. This review comprises different approaches to enhance their solubility, stability and bioavailability of various physical and chemical modifications were made with Andrographolide. The nanotechnology-based approach in formulation shows the significant result to improve the characteristics of phytoconstituents. So various Formulations were developed like Nanoparticles (NPs), Liposome, Nanoemulsion (NE), etc. which multi-fold increases the solubility of AGL. In the modern era along with stability and solubility of the drug, controlled release pattern and targeted drug delivery is also major concern. Therefore,
\end{abstract}

various novel formulations were developed by using a combination of two system approach to enhance safety and efficacy were comprised in the review. This dual approach gives a better therapeutic response as compared to a single nano-carrier system-based approach.

Key words: Andrographolide, Bioavailability, Nanocarriers, Solubility, Stability, Dual approach.

Correspondence

Mr. Rahul Kumar Maurya

National Ayurveda Research Institute for Panchakarma, Cheruthuruthy, Thrissur-679 531, Kerala, INDIA.

Email id: mauryabrahul@gmail.com

DOI: 10.5530/jyp.2022.14.3

\section{INTRODUCTION}

There are several medicinal plants that are used in the Indian traditional health care system from ages to treat various abnormalities. In these Andrographis paniculata belongs to the Acanthaceae family, which is also called Kalmegh, ${ }^{1}$ a widely used plant for several viral infections. Andrographis paniculata has Andrographolide (AGL) as a major phytoconstituents which is a chemically diterpenoid ring.

AGL is reported for anti-microbial, ${ }^{2}$ anti-inflammatory ${ }^{3}$ hypotensive, ${ }^{4}$ anti-diabetic, antioxidant activity, and hepatoprotective activity. ${ }^{5}$ $\mathrm{Xu}$ et al. 2006 define the activity of the Andrographis paniculata against nine bacterial species including Salmonella typhimurium, Escherichia coli, Shigella sonnei, Staphylococcus aureus, Pseudomonas aeruginosa, Streptococcus pneumonia, Streptococcus pyogenes, Legionella pneumophila, and Bordetella pertussis. Chao et al. 2011 depicted the antiinflammatory effect of Andrographis paniculata was observed by the significant inhibition of NF- $\mathrm{kB}$ luciferase, tumor necrosis factor (TNF- $\alpha$ ), interleukin 6 (IL-6), macrophage inflammatory protein-2 (MIP-2), and nitric oxide (NO) secretions from lipopolysaccharide /interferon- $\gamma$. Thakur et al. 2016 observed the antidiabetic effect of acetylcholinesterase activity in the pre-frontal cortex and hippocampus of diabetic rats was 2.1 to 2.6 times higher compared to non-diabetic rats it exhibited that Andrographolide reduced acetylcholinesterase activity, oxidative stress, and insulin deficiency.

\section{PHARMACOLOGICAL ACTION}

\section{Wound healing}

AGL plays a significant role in wound healing. The pharmacological mechanism behind wound healing is the higher epithelisation rate, Upregulation of human collagen I expression, Stimulation of formation of collagen fiber, Proliferation, and angiogenesis of tissue. ${ }^{6}$ AGL has multidimensional approaches for the effective management of wound healing. Various healing mechanisms associated with AGL are shown in Figure 1. It creates pharmaceutical attraction for the development of topical formulation.

\section{Anti-inflammatory activity}

AGL significantly inhibits the NF- $\kappa \mathrm{B}$ luciferase, tumor necrosis factor (TNF- $\alpha$ ), interleukin 6 (IL-6), macrophage inflammatory protein-2 (MIP-2), and nitric oxide (NO) secretions from lipopolysaccharide / interferon- $\gamma$, as a result, a potent anti-inflammatory effect was observed in an animal model.

\section{Hepatoprotective}

AGL has a potent hepatoprotective action. ${ }^{7}$ Stimulation of Glutathione level, inhibition of lipid peroxidase, and free radical scavenging activity is the major pharmacological pathway of AGL, to protect and strengthen hepatic cells ${ }^{8}$ shown in Figure 2.

Various pharmacological models like carbon tetrachloride, galactosamine, lipopolysaccharide, ${ }^{9}$ Plasmodium berghei, ${ }^{10}$ paracetamolinduced liver toxicity ${ }^{11}$ were developed to establish the hepatoprotective action of AGL.

\section{Antiviral activity}

Andrographis paniculata were also reported for antiviral activity against herpes simplex virus (HSV), HIV, flaviviruses, and pestiviruses. AGL increases the level of $\mathrm{CD} 4^{+}$lymphocytes which significantly increases the immunological response which is weakened by the HIV virus.

\section{Antipyretic and analgesic activity}

Andrographis paniculata extract consists of a series of active phytoconstituents like phenolic acids, flavonoids, triterpenes, terpenoid 


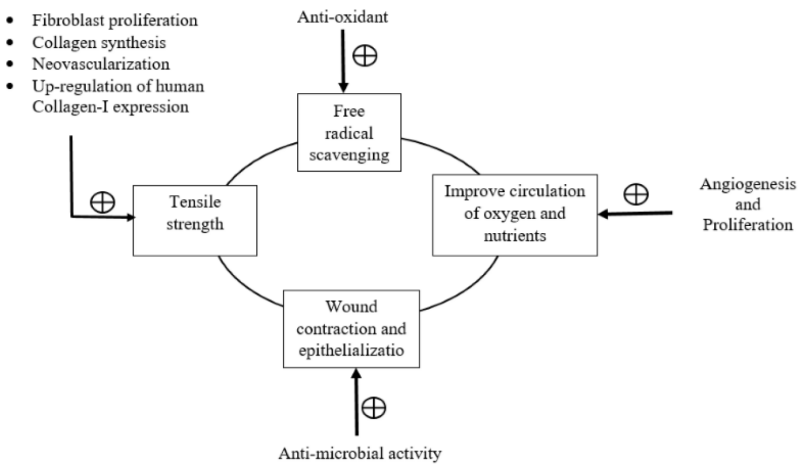

Figure 1: Wound healing activity of Andrographolide.

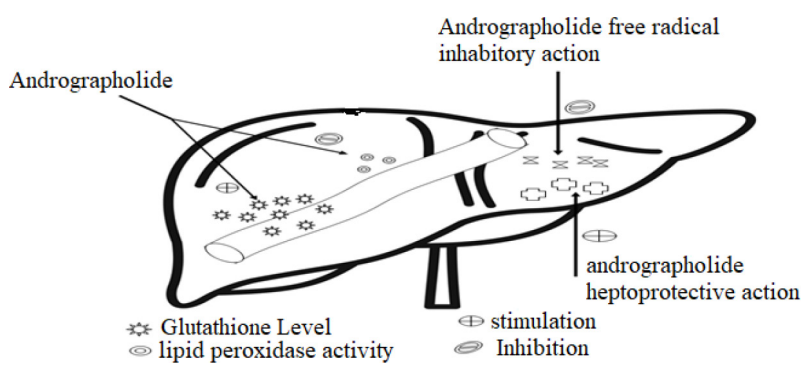

Figure 2: Hepatoprotective action of Andrographolide.

lactones, and volatile compounds. Various studies on animal models exhibited that terpenoid lactones and flavonoid shows antipyretic and analgesic activity. ${ }^{12,13}$

\section{Antibacterial activity}

Andrographis paniculata is effective against nine bacterial species including Salmonella typhimurium, Escherichia coli, Shigella sonnei, Staphylococcus aureus, Pseudomonas aeruginosa, Streptococcus pneumonia, Streptococcus pyogenes, Legionella pneumophila, and Bordetella pertussis.

\section{Antidiabetic activity}

AGL is effective against both type I and type II diabetes. ${ }^{14}$ A recent study on gene expression reveals that AGL increases the hepatic apelin gene expression as a result the levels of blood glucose significantly decrease in blood plasma.

\section{Anticancer activity}

Many clinical studies exhibited that AGL has anticancer activity. Various mechanisms were suggested for their anticancer effect shown in Figure 3. Researchers depicted that up-regulation of tumor suppressor elements and down-regulation of tumor progression elements is the characteristics pathway followed by AGL to represent their anticancer activity. Down-regulation of cell cyclin protein CDK4 and up-regulation tumor necrosis factor caused by AGL is a selective mechanism behind the anticancer activity. ${ }^{15}$ The Anticancer activity of AGL was observed by the induction of apoptosis. ${ }^{16}$ Chao et al. reported that down-regulation of cell growth, apoptosis, anti-angiogenesis, and anti-transformation is the major pathway of AGL to inhibit cancer cell growth. ${ }^{17}$

Lim et al. exhibited that down-regulation of tyrosine kinase, cyclin kinase, and growth factor and up-regulation of Apoptotic protein is the potential mechanism of AGL against cancerous cells. ${ }^{18}$ Kumar et al. reveal that down-regulation of cell proliferation shows significant anticancer

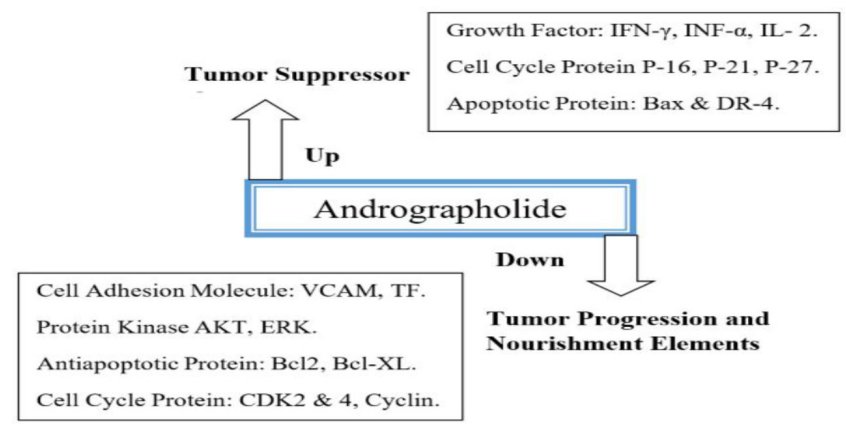

Figure 3: Anticancer/Antitumor activity of Andrographolide.

activity in HT-29 (colon cancer) cells. ${ }^{19}$ Jada et al. also exhibited anticancer activity of AGL against breast cancer cell line (MCF-7) and colon cancer cell line (HCT-116). ${ }^{20}$ Song et al. reported the anticancer activity of AGL against breast cancer cell line (MCF-7), Human colon cancer (HCT 116), and Human prostate cancer (DU 145). ${ }^{21}$ The basis of various clinical studies of AGL on different cell lines exhibited that up-regulation of tumor suppressor elements like growth factor, cell cycle protein, and apoptotic protein, and down-regulation of tumor progression and nourishment elements like cell adhesion molecule, an anti-apoptotic protein, and protein kinase is the key factor to control abnormal growth of the cell.

Various clinical studies reveal that AGL has many pharmacological actions however, AGL was not depicted expediential therapeutic response due to their poor bioavailability and stability. ${ }^{22}$ AGL exhibited poor absorption and low bioavailability during oral administration. The major cause of AGL instability are First-pass metabolism, gastric instability hydrolysis in weak basic medium, biliary excretion, terminal intestinal P-glycoprotein excretion. ${ }^{23}$ Poor aqueous solubility and high lipophilicity are the major cause for poor bioavailability. ${ }^{24}$

The major concern behind the designing of drug delivery system is to improve stability as well as solubility of AGL. Localized delivery minimizes the first pass and pre-systemic metabolism of AGL and enhances the therapeutic potential. ${ }^{25}$

Topical application has site-specific drug delivery and also becomes patient compliance in case of wound healing. The therapeutic effect of topical preparation is limited by slow penetration or release of drug from the system at the wound. To overcome this hurdle various pharmaceutical approaches were made to improve the solubility, permeability, and bioavailability of AGL. Various nanotechnologybased drug delivery systems like liposomes, nanoparticles, nanospheres, nanofibers, nanocapsules, nanoemulsions, nanosponges, etc were developed to improve stability, solubility, entrapment efficiency, and potency of AGL ${ }^{26}$ given in Table 1. Different nanocarriers were designed and optimized by the researchers but still, challenges are present to get a desirable response. Dual approach was incorporated to overcome the limitation present in the available drug delivery system.

\section{DUAL APPROACHES BASED DRUG DELIVERY SYSTEM}

\section{Cyclodextrin based nanocarriers}

In this novel approach, cyclodextrin combines with the nanocarrier to improve entrapment efficiency, solubility, and stability of phytoconstituents. ${ }^{27}$

Cyclodextrin is a stable macromolecule derived from the enzymatic degradation of starch. It has a cage-like structure with have lipophilic inner cavity and hydrophilic outer surface. They are water-soluble 


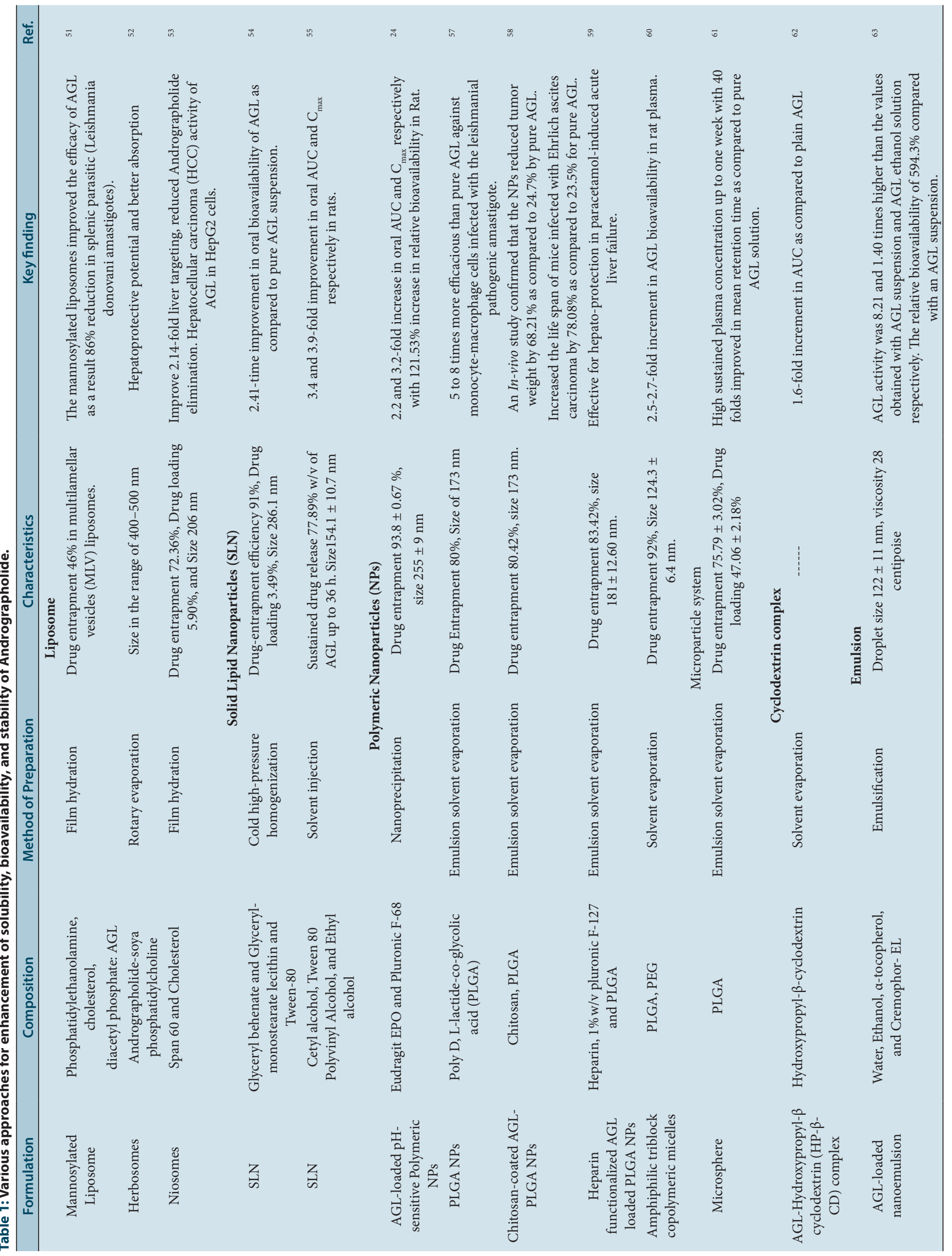




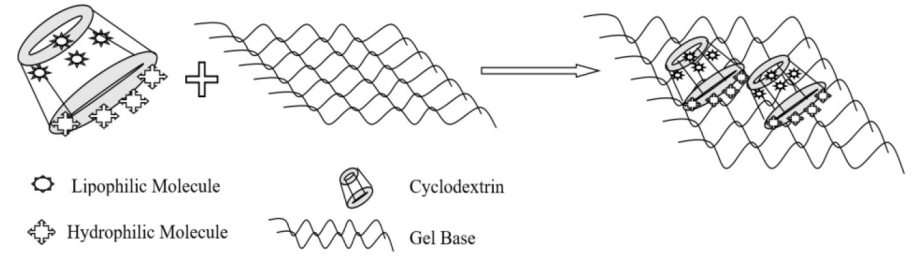

Figure 4: Cyclodextrin based nanocarriers.

and biocompatible. Chemically they are made up of glucopyranose units. Specific truncate shapes appear due to chair conformation of glucopyranose unit shown in Figure 4. Improvement in the therapeutic efficacy of curcumin was found to be improved when delivered from the cyclodextrin-based liposome. ${ }^{28}$ Increase retention time of doxorubicin in tumor cells when administered lipid carrier along with cyclodextrin. ${ }^{29}$ The therapeutic efficacy of camptothecin nanosponge is increased when it combined with cyclodextrin. ${ }^{30}$

A novel system prepared by the combination of Cyclodextrin with nanocarrier has acted as potential nanocarriers. ${ }^{31}$ Nanosponges are polymeric Cyclodextrin inclusion systems mostly used for the delivery of phytoconstituent like Camptothecin, Paclitaxel, Quercetin, Curcumin, and Andrographolide. As a result of cross-linking of cyclodextrin unit nanoporous structure gets developed, it increases the entrapment, solubility, stability, permeation, release characteristics, and bioavailability. ${ }^{32}$

Loading of nanocarrier into hydrogel structure encourages the delivery of lipophilic materials. ${ }^{33,34}$ Pushpalatha et al. 2019 reported that transdermal co-delivery of Curcumin (CUR) and Resveratrol (RES) using Cyclodextrin nanosponge-based hydrogel and studied for synergism against breast cancer cells. Gidwani et al. 2015 exhibited that a combination of Cyclodextrin and nanotechnology improves the aqueous solubility of chemotherapeutic agents.

\section{Chitosan-hyaluronic based lipid carrier nanocomposite sponges (CHNS)}

In another dual or combination approach nanostructured lipid carrier was developed by solvent diffusion method further incorporated into the chitosan-hyaluronic acid gel and lyophilized to make nanocomposite sponges $^{35}$ shown in Figure 5. Chitosan is a linear polysaccharide made up of D-Glucosamine and N-acetyl D-glucosamine. It is a biodegradable polymer that is the most commonly used polymer in drug delivery systems. The application of chitosan in the field of surgical dressing and wound healing is presumable by its mucoadhesive and homeostatic properties. ${ }^{36}$ However, the brittleness of polymer is the major concern in formulating surgical dressing materials, which could be rectified by the incorporation of other polymers such as hyaluronic acid (HA) ${ }^{37}$

Hyaluronic acid is a derived polysaccharide and has a humectant property that encourages wound healing by preventing dryness of tissue. Besides, it stimulates collagen secretion at the injured tissue by the proliferation of fibroblast as a result optimistic observed on scarless wound healing. ${ }^{38}$ Therefore, a combination approach CHNS can overcome the aforementioned hurdle. Solid lipid nanoparticles (SLN) and nanostructured lipid carriers (NLCs) have selective skin permeability and localization but still, responses are limited due to their inadequate rheological behavior. Therefore, the implementation of a combination approach (CHNS) by the incorporation of nanocarrier in secondary vehicles. The developed CHNS system elaborates its application and benefits. The dual approach enhances the consistency of final formulations and promotes the long-term stability of the incorporated nanocarriers. ${ }^{39}$

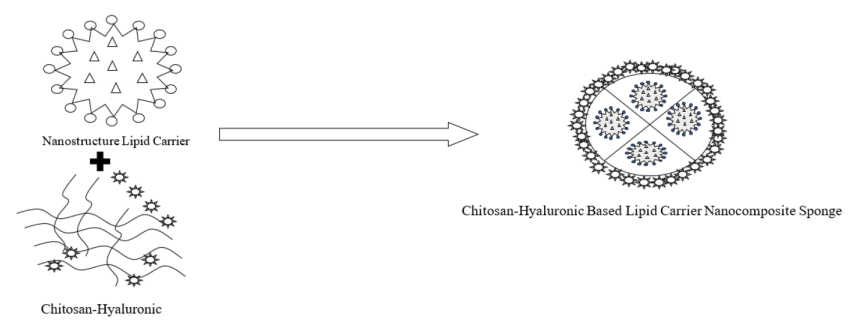

Figure 5: Chitosan-Hyaluronic based lipid carrier nanocomposite sponges.

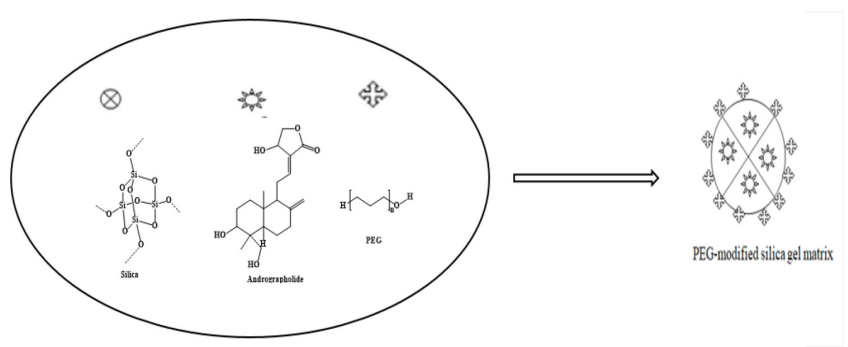

Figure 6: Andrographolide loaded PEG-modified silica gel matrix. PEG; Polyethylene Glycol

\section{PEG-modified silica gel matrix}

Some other dual approaches were also reported by the researchers to design a controlled release formulation of AGL, in this approach the efficacy of the formulation was improved by preparing a PEG-modified silica matrix. ${ }^{40}$ Figure 6 . Like other approaches, this dual approach is also significant to design an extended drug delivery system for AGL. The amorphous and porous characteristic of silica provides better entrapment, prolongs residence time, and enhances the therapeutic effect of the drug. ${ }^{41}$ The use of porous and nonporous silica may affect drug loading capacity, porous silica has a major prevalence over non-porous because porous silica has a greater surface area for drug loading. ${ }^{42}$ Drug release can be regulated by the pore size of the silica; it can be controlled by using organic additives like polyethylene glycol (PEG) ${ }^{43}$ Chakraborty et al. ${ }^{44}$ reported almost $80 \%$ release of AGL accompanied with the highest burst release was obtained exclusively the highest concentration of PEG $(12 \% \mathrm{w} / \mathrm{w})$ in silica. The bioavailability of AGL was found $168 \mathrm{hr}$ in silica carrier while in the case of crude material it was observed nil after $7 \mathrm{hr}$. Kinetic results reveal the initial $6 \mathrm{hr}$ release was rapid and subsequent slow release in the following stage (up to $168 \mathrm{hr}$ ). The releasing pattern of AGL was observed rapidly from the Superficially layer at the first phase and slow-release in the second phase from the inner pore of the silica matrix. A three-dimensional network of silica immobilized AGL effectively controlled the release rate of the drug. ${ }^{45}$

\section{PLGA nanoparticle embedded into the gelatin-based hydrogel}

Another dual approach is based on the formulation of AGL-PLGA nanocarriers incorporated in gelatin-based hydrogel (GBH) to design an extended drug delivery system. AGL-PLGA nanoparticles were prepared by emulsion solvent evaporation method and embedded into the gelatinbased hydrogel Figure 7. The terminal ester group present in PLGA shows a significant role in the modified release behavior of AGL. However, the combination approach of GBH with AGL-PLGA nanoparticles prolongs the release of AGL for more than 1 month. The combination carriers of PLGA and GBH significantly impact the release pattern of AGL. 

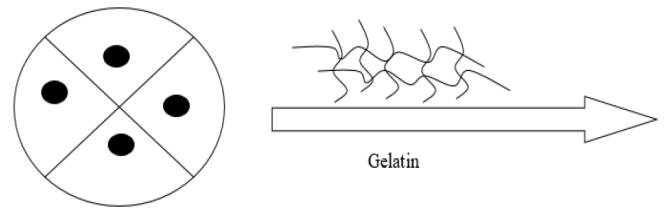

Andrographolide

Q PLGA

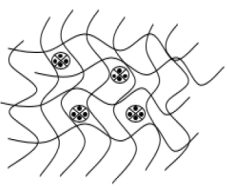

Gelatin Based Hydrogel

Figure 7: PLGA nanoparticle embedded into the gelatin-based hydrogel. PLGA; Poly D, L-lactide-co-glycolic acid
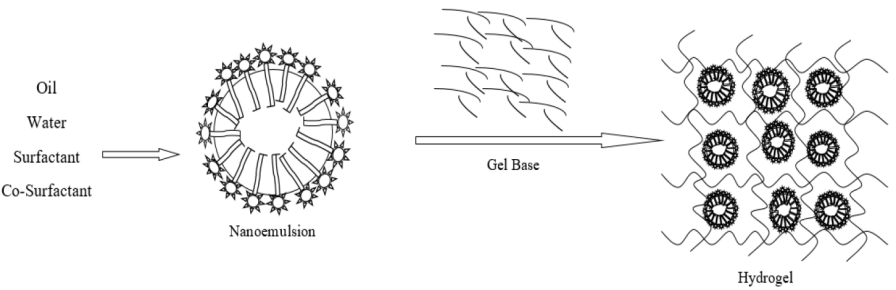

Figure 8: Nanoemulsion-based hydrogel.

Modified release pattern observed due to the difference in hydrophilicity of terminal end group. Results show that the formulation of AGL-NPs embedded into GBH has prolonged retention for almost 2 months for sheet type of hydrogel and more than 2 months for beads type of hydrogel. Therefore, a dual approach-based AGL-NPs embedded GBH is a potent formulation that could minimize the drug administration frequency and extend the duration to improve the clinical effect. ${ }^{46}$

\section{Nanoemulsion-based hydrogel}

Nanoemulsion can improve drug solubility and stability but has limitations for topical application. The incorporation of nanoemulsion into a hydrogel increases the viscosity of the system which can prolong the drug residence time ${ }^{47}$ Figure 8.

Nanoemulsion is composed of oil, water, surfactant, and co-surfactant. ${ }^{48}$ The Characteristics features of nanoemulsion are stability, solubility, and bioavailability. However, nanoemulsion is confined in terms of viscosity that limited their topical application. ${ }^{49}$ This limitation can be overcome by incorporating nanoemulsion into a hydrogel. The formation of hydrogel imparts significant viscosity and prolong drug residence time..$^{50}$ Carbopol was employed as the gelling agent, whereas other excipients are propylene glycol, oleic acid, triethanolamine, methylparaben, and propylparaben were also added to produce hydrogel base.

\section{CONCLUSION}

AGL has a broad range of therapeutic potential but their clinical response is restricted due to their poor aqueous solubility, stability in oral administration, and low bioavailability. Various modern approaches were made to improve the limitation associated with AGL. Based on previous research it was concluded dual approach or combination of nanocarrier systems efficiently overcome the hurdle associated with AGL delivery and potentiate its clinical response, a similar approach can be made for the other kind of phytoconstituent.

\section{ACKNOWLEDGEMENT}

This review was acknowledged to The Director, National Ayurveda Research Institute for Panchakarma, Cheruthuruthy under the affiliation of the Central Council for Research in Ayurvedic Sciences, New Delhi for the encouragement.

\section{CONFLICT OF INTEREST}

The authors declare that there is no conflict of interest.

\section{REFERENCES}

1. Al-Bayaty FH, Abdulla MA, Hassan MIA, Ali HM. Effect of Andrographis paniculata leaf extract on wound healing in rats. Natural Product Research. 2012;26(5):423-9.doi: 10.1080/14786419.2010.496114.

2. $Y X, R L M, T K S M$. An investigation on the antimicrobial activity of Andrographis paniculata extracts and andrographolide in vitro. As J Plant Sci. 2006;5(3):527-30. doi: 10.3923/ajps.2006.527.530.

3. Chao W, Kuo Y, Hsieh S, Lin B. Inhibitory Effects of Ethyl Acetate Extract of Andrographis paniculata on NF- $\kappa$ B Trans-Activation Activity and LPS-Induced Acute Inflammation in Mice. Evidence-Based Complementary and Alternative Medicine. 2011;2011:1-9. doi: 10.1093/ecam/nep120.

4. Subramanian $\mathrm{R}$, Asmawi $\mathrm{MZ}$, Sadikun A. In vitro alpha-glucosidase and alpha-amylase enzyme inhibitory effects of Andrographis paniculata extract and andrographolide. Acta Biochim Pol. 2008;55(2):391-8. doi: 10.18388/ abp.2008_3087.

5. Hazra M, Mandal DD, Mandal T, Rao BP, Samaddar S. Optimization and characterization of hepatoprotective andrographolide microspheres in the necrotic rat model. J Drug Del Sci Tech. 2021: 1(65): 1-12.

6. Buntrock P, Jentzsch KD, Heder G. Stimulation of wound healing, using brain extract with fibroblast growth factor (PGF) activity: II. Exp Pathol. 1982;21(1):62-7. doi: 10.1016/S0232-1513(82)80054-6.

7. Dai Y, Chen SR, Chai L, Zhao J, Wang Y, Wang Y. Overview of pharmacological activities of Andrographis paniculataandits major compoundandrographolide. Crit Rev Food Sci Nutr. 2019;59(sup1):S17-29. doi: 10.1080/10408398.2018.1501657.

8. Ye JF, Zhu H, Zhou ZF, Xiong RB, Wang XW, Su LX, et al. Protective mechanism of andrographolide against carbon tetrachloride-induced acute liver injury in mice. Biological and Pharmaceutical Bulletin. 2011;34(11):1666-70. doi: 10.1248/ bpb.34.1666.

9. Pan CW, Yang SX, Pan ZZ, Zheng B, Wang JZ, Lu GR, et al. Andrographolide ameliorates d-galactosamine/lipopolysaccharide-induced acute liver injury by activating Nrf2 signaling pathway. Oncotarget. 2017;8(25):41202-10. doi: 10.18632/oncotarget.17149.

10. Chander R, Srivastava V, Tandon And JS, Kapoor NK. Antihepatotoxic activity of diterpenes of Andrographis paniculata (Kal-Megh) against Plasmodium berghei-induced hepatic damage in Mastomys natalensis. Int J Pharmacogn 1995;33(2):135-38. doi: 10.3109/13880209509055213.

11. Visen PKS, Shukia B, Patnaik GK, Dhawan BN. Andrographolide protects rat hepatocytes against paracetamol-induced damage. J Ethnopharmacol. 1993;40(2):131-36. doi: 10.1016/0378-8741(93)90058-D.

12. Kumar S, Singh B, Bajpai V. Andrographis paniculata (Burm. f) Nees. Traditional uses, phytochemistry, pharmacological properties and quality control/quality assurance. J Ethnopharmacol. 2021. PMID 114054.

13. Ilmi $H$, Pamungkas IR, Tumewu L, Hafid AF, Widyawaruyanti A. Analgesic and antipyretic activities of ethyl acetate fraction tablet of Andrographis paniculata in animal models. Evid-based compl alt. Med. 2021;2021.

14. Kandanur SGS, Tamang N, Golakoti NR, Nanduri S. Andrographolide: A natural product template for the generation of structurally and biologically diverse diterpenes. Eur J Med Chem. 2019;176:513-33. doi: 10.1016/j. ejmech.2019.05.022.

15. Rajagopal S, Kumar RA, Deevi DS, Satyanarayana C, Rajagopalan R Andrographolide, a potential cancer therapeutic agent isolated from Andrographis paniculata. J Exp Ther Oncol. 2003;3(3):147-58. doi: 10.1046/j.1359-4117.2003.01090.x.

16. Kansom T, Sajomsang W, Saeeng R, Charoensuksai $P$, Opanasopit $P$, Tonglairoum $P$. Apoptosis induction and antimigratory activity of andrographolide analog (3a. 1-incorporated self-assembled nanoparticles in cancer cells. AAPS Pharm Sci Tech. 2018;19(7):3123-33.

17. Chao HP, Kuo CD, Chiu JH, Fu SL. Andrographolide exhibits anti-invasive activity against colon cancer cells via inhibition of MMP2 activity. Planta Med. 2010;76(16):1827-33. doi: 10.1055/s-0030-1250039

18. Lim JCW, ChanTK, Ng DS, Sagineedu SR, Stanslas J, WongWF. Andrographolide and its analogues: Versatile bioactive molecules for combating inflammation and cancer. Clin Exp Pharmacol Physiol. 2012;39(3):300-10. doi: 10.1111/j.14401681.2011.05633.x.

19. Ajaya Kumar R, Sridevi K, Vijaya Kumar N, Nanduri S, Rajagopal S. Anticancer and immunostimulatory compounds from Andrographis paniculata. $J$ Ethnopharmacol. 2004;92(2-3):291-95. doi: 10.1016/j.jep.2004.03.004.

20. Jada SR, Subur GS, Matthews C, Hamzah AS, Lajis NH, Saad MS, et al. Semisynthesis and in vitro anticancer activities of andrographolide analogues. Phyto Chemistry. 2007;68(6):904-12. doi: 10.1016/j.phytochem.2006.11.031.

21. Song Y, Xin Z, Wan Y, Li J, Ye B, Xue X. Synthesis and anticancer activity of some novel indolo [3, 2-b] andrographolide derivatives as apoptosis-inducing agents. Eur J Med Chem. 2015;90:695-706. doi: 10.1016/j.ejmech.2014.12.017. 
22. Pawar A, Rajalakshmi S, Mehta P, Shaikh K, Bothiraja C. Strategies for formulation development of andrographolide. RSC Adv. 2016;6(73):69282-300. doi: 10.1039/C6RA12161F

23. Mishra N, Yadav KS, Rai VK, Yadav NP. Polysaccharide encrusted multilayered nano-colloidal system of andrographolide for improved hepatoprotection. AAPS Pharm Sci Tech. 2017;18(2):381-92. doi: 10.1208/s12249-016-0512-4.

24. Chellampillai B, Pawar AP. Improved bioavailability of orally administered andrographolide from $\mathrm{pH}$-sensitive nanoparticles. Eur J Drug Metab Pharmacokinet. 2011;35(3-4):123-29. doi: 10.1007/s13318-010-0016-7.

25. Pushpalatha R, Selvamuthukumar S, Kilimozhi D. Cyclodextrin nanosponge based hydrogel for the transdermal co-delivery of curcumin and resveratrol: Development, optimization, in vitro and ex vivo evaluation. J Drug Deliv Sci Technol. 2019;52:55-64. doi: 10.1016/j.jddst.2019.04.025.

26. Escobar-Chávez JJ, Díaz-Torres R, Rodríguez-Cruz IM, Domínguez-Delgado $\mathrm{CL}$, Morales RS, Ángeles-Anguiano E, et al. Nanocarriers for transdermal drug delivery. Res Rep Transder Drug Deli. 2012;1:3-17.doi: 10.2147/RRTD.S3261.

27. Gidwani B, Vyas A. A comprehensive review on cyclodextrin-based carriers for delivery of chemotherapeutic cytotoxic anticancer drugs. BioMed Res Int. 2015;2015:1-15. doi: 10.1155/2015/198268.

28. Dhule SS, Penfornis P, Frazier T, Walker R, Feldman J, Tan G, et al. Curcuminloaded $\gamma$-cyclodextrin liposomal nanoparticles as delivery vehicles for osteosarcoma. Nanomedicine: Nanotechnology Biology and Medicine. 2012;8(4):440-51.doi: 10.1016/j.nano.2011.07.011.

29. Arima H, Hagiwara Y, Hirayama F, Uekama K. Enhancement of antitumor effect of doxorubicin by its complexation with $\gamma$-cyclodextrin in pegylated liposomes. $J$ Drug Target. 2006;14(4):225-32. doi: 10.1080/10611860600711136.

30. Swaminathan S, Pastero L, Serpe L, Trotta F, Vavia P, Aquilano D, et al. Cyclodextrin-based nanosponges encapsulating camptothecin: Physicochemical characterization, stability and cytotoxicity. Eur J Pharm Biopharm. 2010;74(2):193-201. doi: 10.1016/j.ejpb.2009.11.003.

31. Gonzalez-Gaitano G, Isasi JR, Velaz I, Zornoza A. Drug carrier systems based on cyclodextrin supramolecular assemblies and polymers: Present and perspectives. Curr Pharm Des. 2017;23(3):411-32. doi: 10.2174/138161282366 6161118145309.

32. Swaminathan S, Cavalli R, Trotta F. Cyclodextrin-based nanosponges: A versatile platform for cancer nanotherapeutics development. WIREs Nanomed Nanobiotechnol. 2016;8(4):579-601. doi: 10.1002/wnan.1384.

33. Gu D, O'Connor AJ, G.H. Qiao G, Ladewig K. Hydrogels with smart systems for delivery of hydrophobic drugs. Expert Opinion on Drug Delivery. 2017;14(7):879-95. doi: 10.1080/17425247.2017.1245290

34. Larrañeta E, Stewart S, Ervine M, Al-Kasasbeh R, Donnelly RF. Hydrogels for hydrophobic drug delivery. Classification, synthesis and applications. J Funct Biomater. 2018;9(1):13. doi: 10.3390/jfb9010013.

35. Sanad RA, Abdel-Bar HM. Chitosan-hyaluronic acid composite sponge scaffold enriched with andrographolide-loaded lipid nanoparticles for enhanced wound healing. Carbohydrate Polymers. 2017;173:441-50. doi: 10.1016/j. carbpol.2017.05.098.

36. Deng CM, He LZ, Zhao M, Yang D, Liu Y. Biological properties of the chitosangelatin sponge wound dressing. Carbohydrate Polymers. 2007;69(3):583-89. doi: 10.1016/j.carbpol.2007.01.014.

37. Mohandas A, Anisha BS, Chennazhi KP, Jayakumar R. Chitosan-hyaluronic acid/NEGF loaded fibrin nanoparticles composite sponges for enhancing angiogenesis in wounds. Colloids and Surfaces B: Biointerfaces. 2015;127:105-13. doi: 10.1016/j.colsurfb.2015.01.024

38. Anisha BS, Biswas R, Chennazhi KP, Jayakumar R. Chitosan-hyaluronic acid/Nano silver composite sponges for drug resistant bacteria infected diabetic wounds. Int J Biol Macromol. 2013;62:310-20. doi: 10.1016/j.ijbiomac.2013.09.011.

39. Oyarzun-Ampuero F, Vidal A, Concha M, Morales J, Orellana S, Moreno-Villoslada I. Nanoparticles for the treatment of wounds. Curr Pharm Des. 2015;21(29):4329-41. doi: 10.2174/1381612821666150901104601.

40. Chakraborty S, Biswas S, Sa B, Das S, Dey R. In vitro and in vivo correlation of release behavior of andrographolide from silica and PEG assisted silica ge matrix. Colloids and Surfaces A: Physicochemical and Engineering Aspects. 2014;455:111-21.doi: 10.1016/j.colsurfa.2014.04.046.

41. Lang Y, Finn DP, Pandit A, Walsh PJ. Pharmacological activity of ibuprofen released from mesoporous silica. J Mater Sci: Mater Med. 2012;23(1):73-80 doi: 10.1007/s10856-011-4488-z.

42. Prokopowicz M, Łukasiak J. Synthesis and in vitro characterization of freezedried doxorubicin-loaded silica/PEG composite. Journal of Non-Crystalline Solids. 2010;356(33-34):1711-20. doi: 10.1016/j.jnoncrysol.2010.06.024.

43. Lorenzi A, Montenero A, Gnappi G, Fiori F. Sol-gel silicon alkoxides-polyethylene glycol derived hybrids for drug delivery systems. J Appl Biomater Biomech. 2010;8(1):14-9. doi: 10.1177/228080001000800103.
44. Brinker CJ, Scherer GW. Sol-gel science: The physics and chemistry of sol-gel processing. Harcourt Barce Ovanovich New York. Academic Press: 2013;2-10.

45. Xu HW, Dai GF, Liu GZ, Wang JF, Liu HM. Synthesis of andrographolide derivatives: a new family of $\alpha$-glucosidase inhibitors. Bioorg Med Chem. 2007;15(12):4247-55. doi: 10.1016/j.bmc.2007.03.063.

46. Kulsirirat T, Sathirakul K, Kamei N, Takeda-Morishita M. The in vitro and in vivo study of novel formulation of andrographolide PLGA nanoparticle embedded into gelatin-based hydrogel to prolong delivery and extend residence time in joint. International Journal of Pharmaceutics. 2021;602. doi: 10.1016/j. ijpharm.2021.120618, PMID 120618

47. Oktavia Indrati RM, Rohman A, Nugroho AK. Development of nanoemulsionbased hydrogel containing andrographolide: Physical properties and stability evaluation. J Pharm Bioallied Sci. 2020;12;Suppl 2:S816-20.

48. Ali A, Ansari VA, Ahmad U, Akhtar J, Jahan A. Nanoemulsion: An advanced vehicle for efficient drug delivery. Drug Res. 2017;67(11):617-31. doi: 10.1055/s0043-115124.

49. Rambharose S, Kalhapure RS, Govender T. Nanoemulgel using a bicephalous heterolipid as a novel approach to enhance transdermal permeation of tenofovir. Colloids and Surfaces B: Biointerfaces. 2017;154:221-27. doi: 10.1016/j. colsurfb.2017.03.040.

50. Mahtab A, Anwar M, Mallick N, Naz Z, Jain GK, Ahmad FJ. Transungual delivery of ketoconazole nanoemulgel for the effective management of onychomycosis. AAPS Pharm Sci Tech. 2016;17(6):1477-90.doi: 10.1208/s12249-016-0488-0.

51. Jayanta Sinha, Sibabrata Mukhopadhy. Targeting of liposomal andrographolide to L. Donovani-infected macrophages in vivo. Drug Deliv. 2000;7(4):209-13.doi: 10.1080/107175400455137.

52. Jain PK, Khurana N, Pounikar Y, Gajbhiye A, Kharya MD. Enhancement of absorption and hepatoprotective potential through soya-phosphatidylcholineandrographolide vesicular system. Journal of Liposome Research. 2013;23(2):110-8.doi: 10.3109/08982104.2012.753456.

53. Sankhyan A, Pawar P. Recent trends in niosome as vesicular drug delivery system. J Appl Pharm Sci. 2012;2(6):20-32. doi: 10.7324/JAPS.2012.2625.

54. Yang $\mathrm{T}$, Sheng $\mathrm{HH}$, Feng NP, Wei H, Wang ZT, Wang $\mathrm{CH}$. Preparation of andrographolide-loaded solid lipid nanoparticles and their in vitro and in vivo evaluations: Characteristics, release, absorption, transports, pharmacokinetics, and antihyperlipidemic activity. J Pharm Sci. 2013;102(12):4414-25. doi: 10.1002/jps.23758.

55. Parveen R, Ahmad FJ, labal Z, Ahmad S. Effect of andrographolide solid lipid nanoparticles (SLNs) on breast cancer. Planta Med. 2013;79(5). doi: 10.1055/s0033-1336547.

56. Roy P, Das S, Bera T, Mondol S, Mukherjee A. Andrographolide nanoparticles in leishmaniasis: Characterization and in vitro evaluations. Int J Nanomedicine. 2010;5:1113-21.

57. Roy P, Das S, Mondal A, Chatterji U, Mukherjee A. Nanoparticle engineering enhances anticancer efficacy of andrographolide in MCF-7 cells and mice bearing EAC. Curr Pharm Biotechnol. 2012;13(15):2669-81.doi: 10.2174/138920112804724855.

58. Roy P, Das S, Auddy RG, Saha A, Mukherjee A. Engineered andrographolide nanoparticles mitigate paracetamol hepatotoxicity in mice. Pharm Res. 2013;30(5):1252-62. doi: 10.1007/s11095-012-0964-5.

59. Zhang J, Li Y, Gao W, Repka MA, Wang Y, Chen M. Andrographolide-loaded PLGA-PEG-PLGA micelles to improve its bioavailability and anticancer efficacy. Expert Opinion on Drug Delivery. 2014;11(9):1367-80. doi: 10.1517/17425247.2014.924503.

60. Jiang Y, Wang F, Xu H, Liu H, Meng Q, Liu W. Development of andrographolide loaded PLGA microspheres: optimization, characterization and in vitro-in vivo correlation. International Journal of Pharmaceutics. 2014;475(1-2):475-84.doi: 10.1016/j.ijpharm.2014.09.016.

61. Zhou H, Lai WP, Zhang Z, Li WK, Cheung HY. Computational study on the molecular inclusion of andrographolide by cyclodextrin. J Comput Aided Mol Des. 2009;23(3):153-62. doi: 10.1007/s10822-008-9247-y.

62. Yen CC, Chen YC, Wu MT, Wang CC, Wu YT. Nanoemulsion as a strategy for improving the oral bioavailability and anti-inflammatory activity of andrographolide. Int J Nanomedicine. 2018;Volume(13):669-80. doi: 10.2147/ IJN.S154824 